\title{
Perfiles
}

ROODY RÉSERVE

\section{El último mosquetero}

No deja de ser un detalle curioso que, veinticinco años después de su muerte, el debate en torno a la memoria de Sartre se haya enfocado en un retrato que elige la Biblioteca Nacional de Francia para la ocasión. Que el gran filósofo, que encandilaba con su prosa, hace un cuarto de siglo, se vea reducido a una discusión de si debe o no ser retratado con un cigarro en la boca, también parece ser una broma de mal gusto, de la cual el mismo Sartre ha de estarse riendo en su descanso eterno.

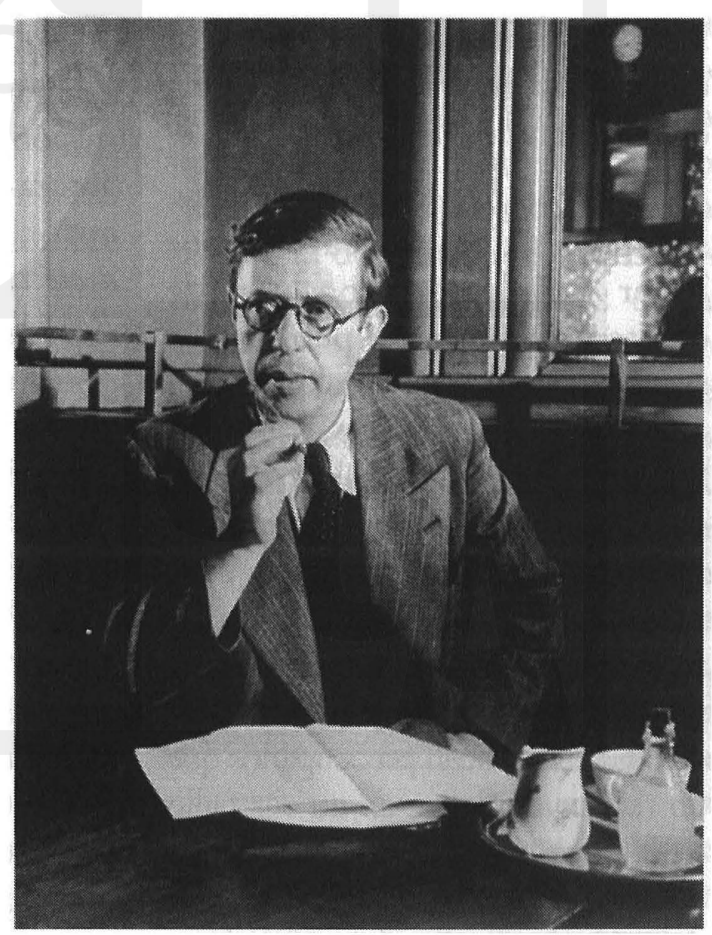


Sartre se reiría -como él mismo lo confesó en ocasión del revuelo que causó el hecho de que rechazara el premio Nobel de literatura que se le concedió en 1972 - de quienes pretendan hoy fijar la esencia de su trabajo en una imagen adaptada a los tiempos postmodernos. Nuestro autor siempre se burló de quienes creen en una pretendida "esencia”. El ser humano está en un completo devenir donde se hace y se transforma. "No naces judío, te vuelves judío, no naces mujer, te vuelves mujer", dijo Sartre. Así, quiso subrayar el carácter de proyecto constante que constituyen los seres humanos. Entonces, si esencia hay, se puede hablar de una esencia siempre en devenir.

El autor de A puerta cerrada, siempre estuvo preocupado por hacer realidad su vocación de escritor. Después de publicar La náusea, en 1938, en una carta a su compañera Simone de Beauvoir, Sartre declaró: "ahora ando en la calle como si fuera un escritor”. De modo que es fácil colegir que a nuestro autor poco le importaría la manera como lo retraten los periódicos de hoy. La superficialidad de quienes se dicen preocupados que un retrato de Sartre en un cigarrillo en la boca pueda infringir la ley en contra de la publicidad del tabaco, dejaría sin duda sin cuidado a nuestro autor. Éste mostró suficiente libertad de espíritu en su vida para que este detalle de la preocupación por la salud de las sociedades post modernas afectara seriamente su buen humor.

A Sartre le importó, más que todo, su vocación de escritor, por mucho que su vida también es una biografía de lucha política. En todo caso, su compromiso político lo vivió como una exigencia de su vocación de escritor. Nunca consideró que el hecho de preocuparse de la política, del diario vivir de sus conciudadanos y de su porvenir, era meterse en cosas que no le incumbían como intelectual. Al contrario, ello le permitía calibrar la dimensión exacta de su misión. Según Annie Cohen-Solal, autora de una reciente biografía del autor de Crítica de la razón dialéctica, citada por el diario $L a$ Razón, éste, "en su juventud era anarquista, alejado de la política y en los años 30 , cuando muchos se movilizaron por la URSS, la guerra civil española o el Frente Popular Francés de 1937, Sartre tuvo como prioridad convertirse en escritor".

El convertirse en escritor permitiría a Sartre defender mejor aquello que siempre consideró como su objetivo primordial: comprender al hombre y defender su dignidad. Para ello, como veremos más adelante, tuvo una 
frenética actividad política. De momento, basta con recordar una frase reveladora que decía nuestro autor en este sentido: "tengo la pasión de comprender a los hombres". De ahí que sostenga Alberés, en su obra Jean Paul Sartre, "la visión de Sartre está limitada al hombre, $y$ al hombre encerrado en sus propios problemas humanos".

Esta última afirmación no significa en modo alguno que Sartre haya hablado del hombre en términos de un ser ensimismado, autónomo y que tenga que habérsela únicamente con sus problemas esenciales, alejado de las cosas y del mundo. Jorge Martínez Contreras en su Sartre la filosofía del hombre, lo expresa en estos términos: "Es claro para nosotros (...) que el problema del hombre es aquel que interesa más profundamente a Sartre, pero que él no considera de ninguna manera que el hombre sea autónomo; por el contrario, y es tal vez en este punto en que reside la fuerza de su filosofía, el hombre depende absolutamente del mundo para existir y termina por desaparecer en él de la misma manera en que surgió: sin razón. Si el hombre autónomo no existe, hay que analizar al universo en su conjunto para comprender lo que Sartre entiende por el hombre".
El hombre para Sartre "es una libertad en situación”. Hablando del yo y su circunstancia, Ortega y Gasset decía que uno no se salva sin el otro. Lo mismo se puede sostener, hablando del hombre sartriano como este ser libre en situación. "Decir que el hombre es una libertad puede inducirnos a error al hacernos crer que hay una naturaleza humana: la libertad. -observa Martínez-. Ahora bien, la libertad no es nada, no es un ser, es la posibilidad de escoger en cada situación: El hombre se define por su proyecto nos dice Sartre. El proyecto es entonces la expresión de la libertad. La libertad y la situación son correlativas: el hombre en situación actúa en tanto que libertad sobre la situación para imponerle su voluntad y, al mismo tiempo, la situación actúa sobre la libertad, desviando o transformando los fines primeros de la acción".

¿Es esta concepción del hombre humanista? No va a responder en un primer momento nuestro autor. El humanismo pretende que existe un Hombre ideal, cuyos pasos debe seguir el hombre concreto. Dice Bernard Henry Lévy al respecto, "Había - hay - un Sartre que sabía que cuando empezamos a asignarles a los hombres concretos la verdad de un Hombre del que no son más que el borrador —cuando decimos: "este hombre 
no es el Hombre, le queda un largo camino por recorrer para llegar a ser el Hombre que es, sin embargo por vocación"- ponemos en movimiento una máquina terrible: la que depurará al hombre concreto para que se parezca a ese hombre ideal, la que sacrificará al hombre actual por un hombre nuevo al que se considera más próximo a esta propiedad, y modelará el hombre nuevo con la carne, la sangre y las cenizas del primero". En definitiva, Sartre denuncia el falso humanismo, el que avasalla y justifica el pillaje y el despojo de los demás.

Pero, finalmente, subraya Henry Lévy, Sartre creó que existe algo propio del hombre. "Cree que el hombre tiene una verdad $\mathrm{o}$, en todo caso, debería tenerla. Cree que los hombres que conoce y observa a su alrededor son, en relación esta Idea, trágicamente incompletos, imperfectos. En otras palabras, cree que su fracaso es remediable. Como cree esto, como cree que la hermosa e impecable Idea del Hombre está ahí, al alcance de la mano, lógicamente invitará a realizarla, a hacer $y$ rehacer al Hombre para que pueda parecerse a ella. Imaginará "otro hombre de mejor calidad" que será el "porvenir del hombre tal como lo conocemos". Aunque, conviene subrayarlo enseguida, ello no significa que este hombre nuevo que hay forjar tendrá que abandonar su libertad y olvidar las situaciones concretas en las que ha de realizarse su sueño humanista.

Unos hombres situados y libres que, a los ojos de Sartre, habría que imitar, fueron los forjados por el comunismo. Después de un viaje a la entonces URSS, exclamó el autor de La náusea: "Allí he encontrado hombres de nuevo cuño". Hoy, a la luz de las revelaciones que se han producido sobre el proceder de los dirigentes políticos, tanto en Rusia como en el otrora bloque soviético, cabe preguntarse si realmente estaba ahí la medida del nuevo hombre que quería Sartre. A este respecto, siguiendo la última entrevista que diera el filósofo antes de su muerte, encontramos la siguiente declaración: "nuestro fin es llegar a un verdadero cuerpo constituido en el que cada persona sea un hombre y donde las colectividades sean también humanas".

Así, hoy se puede decir que Sartre reconoció su error. La declaración circunstancial que diera sobre el proyecto humanista de la URSS, no debe invalidar su sueño de un "nuevo hombre". El autor de El ser y la nada, a estas alturas, estaría dispuesto a reconocer que estábamos lejos del ideal humano que él quería. Tal parece ser la intuición de Ignacio Ellacuría cuando apunta, en su artículo 
denominado "El testamento de Sartre": "Sartre sostiene que individual y colectivamente somos todavía infrahombres. No hemos dado todavía nuestra medida cabal. $\mathrm{Ni}$ la daremos nunca si no renovamos profundamente nuestras relaciones con el próximo, con el otro (...). El paso de la infrahumanidad a la humanidad, el paso de la prehistoria a la historia, como diría Marx, tiene que ver esencialmente con el cambio de las relaciones sociales, con la construcción de una nueva sociedad, definida sobre todo por la calidad nueva de las relaciones entre los hombres". Este era el propósito de Sartre. En alguna medida, su declaración acerca del hombre de nuevo cuño que había encontrado en la Unión Soviética, tenía que ver con el sueño de establecimiento de estas nuevas relaciones sociales.

Desde el punto de vista de su filosofía, Sartre intentó demostrar que "el mundo es humano". Por eso, sostendrá Martínez Contreras que la "ontología de Sartre está impregnada de antropología”. De ahí se explique su preocupación por unir el idealismo y realismo. Nuestro autor hace suya la concepción husserliana según la cual la conciencia siempre es conciencia de algo y que solamente existe en el mundo. En Une idée fondamentale de la phénomólogie de Husserl lo expresó en estos términos: "finalmente todo está fuera, todo hasta nosotros mismos: fuera, en el mundo, entre los otros. No habremos de descubrirnos en algún retiro, sino en el camino, en la ciudad, en medio de la multitud, entre las cosas, entre los hombres".

La acción política, la revolución, es fundamentalmente el medio con que cuentan los más pobres para forzar la llegada de este hombre nuevo y de las nuevas relaciones sociales. En primer lugar, el capitalismo es, por antonomasia,

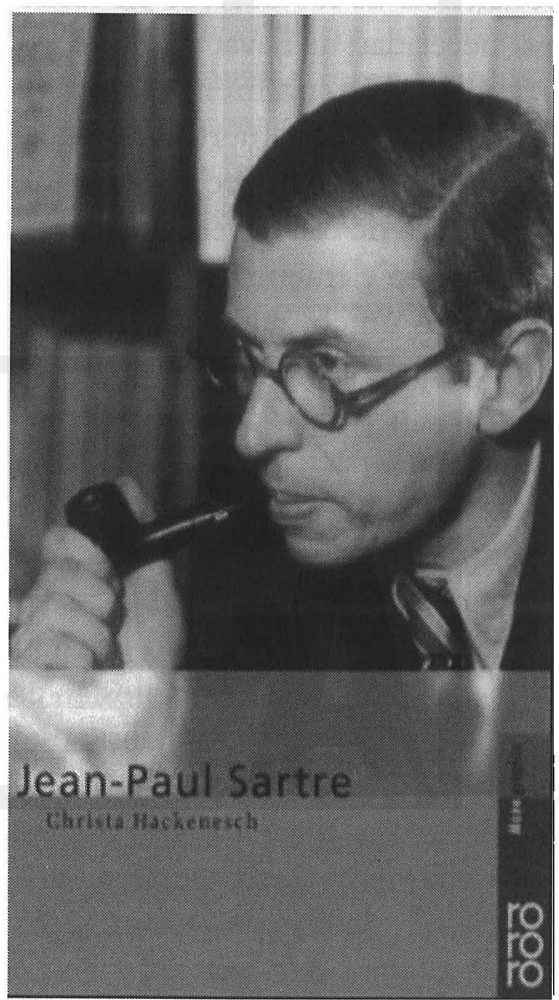


antihumano. Este sistema, por las relaciones sociales que instaura, impedirá la realización del proyecto de nuevo hombre. Por eso Sartre piensa que hay que derribar el muro de la insolidaridad y de la explotación sin fin del hombre por el hombre.

Este combate se ganará, en buena ortodoxia marxiana, cuando los obreros entiendan que tienen que luchar, como clase, en contra de sus opresores, los burgueses. Aunque, nuestro autor estaba claro que no se habían reunido las circunstancias, no existía la plena conciencia de los obreros en torno a la necesidad de llevar adelante esa batalla. "Actualmente-dice Sartre - hay una fuerte tendencia a generalizar el concepto de conciencia de clase y el de lucha de clase como elementos a priori de la lucha. Lo único que existe a priori es la situación objetiva de explotación de la clase. La conciencia nace solamente en la lucha: la lucha de clases no existe mientras no existan lugares donde efectivamente se combate. Es verdad que el proletariado lleva en sí la muerte de la burguesía, es verdad que el sistema capitalista está minado por contradicciones estructurales, pero eso no implica necesariamente a existencia de una conciencia de clase o de una lucha de clase. Para que haya conciencia y lucha es necesario que alguien combata".

En esta tarea de combatir, hace falta cierta organización y cierta vanguardia. Es el triste y esencial papel que tiene que desempeñar el partido comunista en opinión de Sartre. Papel esencial, porque el partido es un instrumento para organizar y dar sentido a la lucha de los explotados. "El partido, con relación a la masa, es una realidad necesaria, porque la masa por sí misma no posee espontaneidad. Triste papel el del partido, porque éste siempre "se desarrolla como un conjunto de instituciones, es decir, como un sistema cerrado, estático y tendiente a la esclerosis. De ahí que siempre esté en retraso con respecto a la masa en fusión, incluso cuando intenta dirigirla, porque la empobrece, porque trata de dominarla, y eso en los casos en que no llega a rechazarla, a desolidarizarse de ella".

Por este hecho de la necesidad del partido, Sartre siempre se mantuvo leal al Partido Comunista Francés (PCF). Siempre se cuidó de ofrecer flancos débiles a los adversarios de la causa comunista. Por eso, en los peores momentos de imperialismo del bloque soviético, él trató de explicar su comportamiento asimilándolo con el enfrentamiento con el capitalismo internacional, el 
antagonismo con los Estados Unidos.

No es que Sartre no tuviera claras las contradicciones existentes en el bloque soviético o que no vislumbrara el comportamiento timorato del PCF. En el prólogo a Les Maos en France declaró: "violencia, espontaneidad, moralidad: éstos son, para los maoístas, los tres caracteres inmediatos de la acción revolucionaria. De ningún modo afirman, simplificando excesivamente las cosas, que "la teoría es la práctica", sino que la teoría no aparece nunca más que en la práctica. De ahí su agilidad para inventar y realizar acciones locales cuyo origen está siempre en las masas (...). Los partidos políticos clásicos de la izquierda han permanecido en el siglo XIX, en la época del capitalismo competitivo. Los maoístas en cambio, con su praxis antiautoritaria se presentan como la única fuerza revolucinaria - aun en sus comienzos - capaz de adaptarse de adaptarse a las nuevas formas de la lucha de clases en el período del capitalismo organizado".

Esta reflexión en torno al autoritarismo de los partidos clásicos de la izquierda, es una crítica al PCF, que Sartre llegó a considerar, en el contexto de los acontecimientos de mayo de 1968, tiene miedo de la revolución. Los comunistas temieron acompañar al pueblo en sus reivindiciones. No quisieron asumir sus responsabilidades ante unas demandas radicales que amenazaron por derrumbar el cimiento mismo de la sociedad capitalista francesa. La constatación de la incapacidad de la izquierda por comprender y empujar la lucha de las masas llevó a Sartre, mucho antes que los acontecimientos de mayo, a romper con el partido comunista. "Siempre he dicho que pensaba de distinta manera que el partido. Eso no es doble juego. A veces conseguía convencerme de que las seudoideas del partido debían contener verdades, apoyarse sobre una base sólida, y que su aparente necedad era sólo superficial. En realidad, me sentía impresionado porque el partido comunista se proclamaba el partido de los obreros. Creo que fue un error. Un intelectual tiene necesidad de encontrar algo a lo que aferrarse y yo encontré eso como tantos otros".

Eso de apoyarse en algo del intelectual, es una preocupación constante en la obra de Sartre. Y, esta idea aparece una y otra vez en su producción propiamente filosófica. El intelectual siente una responsabilidad tremenda para con su mundo. Esta responsabilidad se vive cuasi como una obligación para con los demás. Una obligación 
moral que manda defender la causa de los más oprimidos. "Entiendo que cada conciencia, cualquiera, tiene una dimensión (...) es la dimensión de la obligación. El término obligación es malo, pero para encontrar otro sería preciso casi inventarlo. Entiendo que cada vez que tengo conciencia de cualquier cosa y cada vez que hago cualquier cosa, hay una especie de requerimiento que va más allá de lo real y que hace que lo que quiero hacer entrañe una especie de coacción interior, que es una dimensión de mi conciencia. Toda conciencia debe hacer lo que hace, no porque lo que ella hace sea válido de tal manera, sino todo lo contrario, porque cualquier objetivo que tenga se presenta en ella con carácter de requerimiento, y eso es para mí el punto de partida".

Esta dimensión responsabilidad que Sartre vuelve a destacar en sus últimos instantes de su vida está íntimamente relacionada con su idea que somos-para-el-otro. El otro es el ser por el cual obtenemos nuestra objetividad. Frente al otro somos a la vez esclavos y libres. Esclavos porque nadie puede derogarse a la presencia que coacciona del otro; libres porque en algún momento hay que volverse amo del esclavo. En esta encrucijada nace la moral sartreana. "Lo que hay de característico en la mora es que la acción, al mismo tiempo que aparece como sutilmente obligada, se ofrece también como algo que puede no hacerse. Por consiguiente, cuando uno la hace, se realiza una elección, y una elección libre. Esta coacción tiene algo de hiperreal en cuanto que no determina, en cuanto se presenta como coacción y la elección se hace libremente".

A partir de esta idea de libertad coaccionada se puede explicar la relación de Sartre con Simone de Beauvoir. Una relación de dos personas maduras que decidieron elevarse sobre las conveniencias sociales. Por eso, Sartre tuvo a la misma vez varias amantes con las que compartía su idea según la cual, en alguna medida toda nuestra vida humana tiene que ver con la sexualidad. Pero, por encima de todo, la relación de Sartre con Beauvoir tiene que ver con una relación afectuosa y de fidelidad (más que todo intelectual) mutua. En los últimos momentos de su vida, Beauvoir será su fiel compañera, quien le ayudó a completar algunas ideas todavía imprecisas. Sobre la importancia y la intimidad de la colaboración mutua entre Sartre y Beauvoir, ésta última, en su obra, La ceremonia del adiós, le presta las siguientes palabras a nuestro autor: "Sería necesario un pensamiento que fuera verdaderamente concebido por ti y por mí al mismo tiempo, en la acción del pensamiento, con las 
modificaciones en cada uno que provoca el pensamiento del otro, $y$ sería necesario llegar a un pensamiento nuestro, es decir, en el que tú te reconocieras pero, al mismo tiempo me reconocieras, $y$ yo me reconociera reconociéndote".

Más adelante, en la misma línea de la colaboración cercana con Beauvoir, sostiene Sartre: "De hecho, no estoy muerto, como bebo, pero lo estoy en cuanto mi obra, ya terminada... Mis relaciones con todo lo que he escrito hasta ahora ya no son las mismas; yo trabajo contigo, tú tienes unas ideas que no son las mías y que me harán ir en ciertas direcciones que yo no tomaría. Por consiguiente, estoy haciendo algo nuevo; lo hago como una última obra $y$, al mismo tiempo, como una obra aparte, que no pertenece al conjunto, aunque, naturalmente, tenga con él algunos rasgos comunes: por ejemplo el concepto de libertad".

En estas últimas palabras de Sartre se intuye la confianza depositada en Simone de Beauvoir $y$, al mismo tiempo, la angustia con que vive sus últimos días. No podría ser de otra manera. La angustia, ante el absurdo de la existencia y la nada del ser que nos aturde. "Y yo, abúlico, lánguido, obsceno, dirigiendo, agitando sombríos pensamiento, también yo estaba de sobra...". "Éramos un montón de existentes molestos, embarazados de nosotros mismos, no había la más mínima razón para que estuviésemos ahí, ni unos ni otros, cada existente, confuso, vagamente inquieto, se sentía de más con relación a los otros". Así describió en La náusea esta sensación de absurdo ante la existencia que experimentó.

Esta filosofía, que afirma que la existencia precede a cualquier esencia, luego, se denominó existencialismo. Sartre es considerado como el padre fundador. A diferencia de los existencialistas cristianos como Keirkegaard o Jaspers que desembocan en un optimismo teológico, Sartre llevará la constatación de náusea hasta sus últimas consecuencias. Es decir, asumirá sin ambages la realidad de los hombres, más allá de cualquier intervención divina. Por eso, dijo Sartre en algún momento, el existencialismo es un humanismo. Aunque, como hemos dicho, un humanismo de nuevo cuño, que debe leerse, más que todo, como un compromiso para construir un nuevo hombre. "El humanismo no pueden realizarlo, vivirlo más que los hombres, y nosotros, que estamos en un período anterior, que vamos en pos de los hombres que debemos ser o que serán nuestros sucesores, no vivimos el humanis- 
mo más que como lo mejor que hay en nosotros".

Cien años después del nacimiento de Sartre, el 21 de junio de 1905 , sin duda sigue siendo urgente la necesidad de construir el nuevo hombre. El autor de Les mouches, nos legó su increíble confianza en los seres humanos. Algo de eso entendió la multitud que lo acompañó hasta el cementerio el día de su funeral. Sartre siempre creó en la fraternidad. En su crítica de la razón dialéctica, aparece con mucha fuerza este acto de fe en la comunión entre los seres humanos. Quizá esta es la última idea que hay que retener de él. No obstante todos sus errores, el mismo hecho de la miseria en que han caído la izquierda, a quien Sartre otorgó un papel primordial en la lucha por rescatar a la humanidad, nos invita a seguir creyendo en el advenimiento de una nueva humanidad.

\section{BIBLIOGRAFÍA}

Albérés, R. M. Jean Paul Sartre, París, Editorial Universitaires, 1962

Beauvoir, Simone de. La plenitud de la vida, Buenos Aires, Editorial Sudamericana, 1961

La ceremonia del adiós, Madrid, El País,. 2003

Ellacuría I. “El testamento de Sartre”, ECA 387-388, 1981, pp.43-50

Lafarge R.. La Filosofía de Jean Paul Sartre, Madrid, G. Del Toro, 1970

Lévy, Bernard-Henri. El siglo de Sartre, Barcelona, Ediciones B, 2001.

Martínez Contreras, J. Sartre la filosofía del hombre, México, Siglo Veintiuno, 1985.

Riu, F., Ensayos sobre Sartre. Venezuela, Monte Ávila Editores, 1978

Sartre, Jean Paul. Escritos políticos, volúmenes 1 y 3, Madrid, Alianza Universidad, 1986 y 1987. 
A puerta cerrada (teatro), Losada. 1951

“La esperanża ahora”, El País, 16-20 de octubre de 1980

Crítica de la razón dialéctica. Vol. I, Buenos Aires, Editorial Losada, 1970

L'etre et le néant, essai d'ontologie phénoménologique, París, Gallimard, 1943

La nausée, París, Gallimard, 1938

Las moscas (teatro), Buenos Aires, Losada, 1951 